\title{
Ict for Agriculture Knowledge Management in Nigeria: Lessons and Strategies for Improvement
}

\author{
${ }^{1}$ Nnadi, F.N., ${ }^{1}$ Chikaire, J., ${ }^{2}$ Atoma, C.N., ${ }^{1}$ Egwuonwu, H.A., ${ }^{1}$ Echetama, J.A. \\ ${ }^{1}$ Department of Agricultural Extension, \\ Federal University of Technology, Owerri, Imo State, Nigeria. \\ ${ }^{2}$ Department of Agricultural Extension and Managenment Technology, \\ Delta State Polytechnic, Ozoro, Delta State, Nigeria.
}

\begin{abstract}
In this century alone our world is faced with an increasingly complex challenge of feeding its growing population, while assuring an equitable and sustainable development. Scientific and technological progress is generating the knowledge and tools to make this possible. The more recent scientific revolution that is taking place at the turn of the century, based on the emergence of the new areas of science, namely in molecular biology (Biotechnology), in agroecology and sustainable agricultural production, and in information and communication technology, is leading to the growing importance of knowledge in present day agriculture and natural resource management. Knowledge has become the most important factor of production, and it plays a critical role in our capacity to respond to the challenges of food security, poverty eradication and sustainable development. The emergence of information and communication technologies (ICT) in the last decade has opened new avenues in knowledge management that could play important roles in meeting the prevailing challenges related to sharing, exchanging, and disseminating knowledge and technologies. ICT allows capitalizing to a great extent on the wealth of information and knowledge available for agricultural knowledge. The ultimate objectives of agriculture knowledge activities are to come up with results that can advance research more in certain areas, and engender technologies that stakeholders can use to increase production, conserve the environment. The paper thus discusses the valuable contribution of ICT to Agriculture Knowledge Management, gathering storing, retrieving, adapting localizing and disseminating innovations needed by rural farm families and linkages between research and extension systems. We reviewed the situation in Nigeria, lessons for Nigeria and the strategies to be adopted for improvement as well as the challenges related to sharing, exchanging and disseminating agricultural, knowledge.
\end{abstract}

Keywords: ICT, Knowledge, Agriculture, Management, Extension, Research.

\section{Introduction}

Most African economies are dominated by agriculture, which contributes about $17 \%$ to the Gross Domestic Product (GDP), 40\% of exports, employment creation and has the potential to reduce poverty. The agricultural sector has been described as the engine for economic growth and improved livelihoods in Africa (World Bank 2006; Diao et al., 2007). The majority of the population in Sub-Saharan Africa lives in rural areas and depends directly or indirectly on agriculture (Diao et al., 2007). Despite the great potential for agricultural production in Africa, about $73 \%$ of the poor people living in rural areas subsist on less than a dollar a day (UNDP, 2005). About 200 million of the world's hungry people are found in the continent (Millennium Development Goals (MDGs) Technical Support Centre 2004) and available statistics suggest that about one third of Africa's population is malnourished (UNDP 2005). Africa has the highest proportion of people living in extreme poverty in the world arid is the only continent where food production has been falling over the years. Available statistics suggest that about $26 \%$ of Africa's population is malnourished. There has been under investment in the rural areas; inadequate access to markets and unfair market conditions; inadequate access to advanced technologies; weak infrastructure, high production and transport costs, conflicts, HIV/AIDS, natural disasters, deforestation, environmental degradation, loss of biodiversity and dependency on foreign aid.

The number of people living below the poverty line in Sub-Saharan Africa (SSA) is over 180 million, and is expected to exceed 300 million people by the year 2020 . In addition, the per capita food production has continued to decline in SSA. It has been pointed out that the key to reversing this trend is to develop agriculture and industry through science, technology and innovation (ECA 2005). There is a general lack of accurate information on prices and markets for agricultural products (IICD 2006).

Small-scale agriculture and the harvesting of natural resources provide livelihoods for over $70 \%$ of the African population. About $70-80 \%$ of this population lives in the rural areas and is predominantly women. Research, civil society, government and private sector organizations have developed innovative technologies and best practices to modernize small-scale agriculture but most of these technologies do not get to the intended beneficiaries. The old extension service delivery system that was meant to pass on research outputs to farmers in Africa has proved inefficient, and most of these institutions have inadequate machinery and capacity to share and disseminate outputs widely to small-scale farmers and other actors (Madukwe 2006; Richardson, 2006). Perhaps the most important objectives of agricultural extension in developing countries is: to improve the productivity (to attain food self- 
sufficiency/security) and livelihoods of rural farm families. To accomplish this cardinal objective, therefore, extension has as one of it important tasks: the exchange and sharing of information knowledge and skills. Extension therefore is essentially communication, a process whereby various participants arc linked and exchange information, a critical requirement for sustainable development. The paradigm shift in development concept towards participation and sustainability coupled with revolution in the information and communication technologies, has provided opportunities for extension and rural communities to move into the information age (Arokoyo, 2005). The very weak linkages in the Research Extension- Farmer-Input Linkage System (REFILS) in Nigeria as in most developing countries, has been a major limiting factor to increased food productivity and sustainable development. Thus strong linkage complimented by flawless information flow enhanced by the effective use of information and communication technologies (ICTs) by the extension service, will significantly boost agricultural production and improve livelihood in developing countries. In the context of changing paradigms in agricultural extension, where linear information flows are being replaced by pluralistic information flow, new actors such as NGOs, private companies, national agricultural research centers, universities and international donors are emerging in the technology transfer pathway. The potentials of ICT to make agricultural extension and developing countries more effective appear unassailable (Omotayo, 2005).

According to ADB (2003), ICT has become a powerful tool in providing developing countries with unprecedented opportunities to meet vital development goals far more effectively than before. Governments in many developing countries have reduced their direct involvement in agricultural services provision. This creates an even greater challenge for the agricultural extension service to remain relevant and effective. Giving farmers access to a variety of information sources, which are accessible, affordable, relevant and reliable is the ultimate aim of providing agricultural information services (Bheenick and Brizmohun, 1999). This development reflects a need for alternative sources of information rather than a face-to-face, technology-driven donor-promoted information service. ICT have been found as the only way in which agricultural extension can achieve this (Richardson, 2003). ICT is thought therefore to achieve information transfer more effectively than other communication methods in extension and evidence relating to its impact in agricultural extension in some developing countries in Africa, Latin America and south Asia has been widely documented. In countries such as Mauritius, Egypt, India, Bangladesh, Chile, India, Mexico, Peru, South Africa and Uganda, ICT has played a major role in diffusing information to rural communities, and show even much unexpected potential (Munyua, 2000; ADB, 2003). Agricultural extension systems in most developing countries are under-funded and have had mixed effects. Much of the extension information has been found to be out of date, irrelevant and not applicable to small farmers' needs, leaving such farmers with very little information or resources to improve their productivity. ICT helps the extension system in reorienting itself towards the overall agricultural development of small production systems. With the appropriate knowledge, small-scale producers can even have a competitive edge over larger operations. When knowledge is harnessed by strong organization of small producers, strategic planning can be used to provide members with least-cost inputs, better storage facilities, improved transportation links and collective negotiations with buyers (Omotayo, 2005).

\section{Agricultural Development and the Value of Icts}

\section{ICTs are useful in the following areas-}

Improved agricultural, environmental, and food security planning: Planning tools and systems for the agriculture sector are obvious areas where ICTs can add significant value. Planners in ministries and sub-national government generally have a degree of infrastructure and human capacity that can support using traditional computing equipment, although in many cases training is necessary. Geographic Information Systems (GIS) offer agriculture and natural resource management planners an increasingly way to plan for land use, track or estimate environmental impacts, visualize important social data, and compare different agricultural development scenarios. Agricultural and land use planners have used maps as a standard tool for years, but the ability of GIS to remake maps rapidly in response to new data or analysis allows planners new degrees of freedom in foreseeing and preventing disaster, or planning development scenarios (Eastman et al., 1996). Accurate and timely information regarding areas of food surplus and shortages driven by the vagaries of climate can be facilitated through ICT. Such use can contribute to improved food management and food security. The Food Insecurity and Vulnerability Information and Mapping System (FIVIMS), is a national and global initiative that aims to raise awareness of food security issues, improve data quality, promote better use of the information to drive action.

Effective and responsible GIS use demands extensive data sets including detailed data gathered from multiple locations, each geo-referenced (i.e. with location information) so that it can be mapped correctly by the GIS. Large data sets present a human and management challenge, but ICT systems can be deployed to aggregate such data from multiple sources, permitting distributed teams of surveyors to gather data and use the telephone, Internet, or PDAs to record and synchronize survey information to a central database. ICT enables a better understanding of issues such as can be changed and linked to the management and conservation of biodiversity. The power of ICT as an information and networking medium enables citizens to act as environmental enforcement agents, alerting decision makers to compliance infringements while leveraging on their power to reach and influence public opinion. Any programme that provides connectivity has the potential to increase sustainability, given appropriate content and training. Two application areas key to natural resource management are GIS mapping and land registration. ICT can contribute to environmental sustainability by providing public access to information and a means of participation 
by the public in decision making, information dissemination, accountability of governments; public awareness, promotion of best practice techniques and technologies; source of alternative livelihoods; and environmental monitoring, mapping and management (Nnadi, et al, 2010). Effective environmental databases can be used to track the status of various environmental indicators and impacts for sustainable environmental management and protection. China has created a range of national databases for land evaluation and management, population, environment and sustainable development. Other applications have include land cover assessment soil erosion, land use and cultivated land by slope and steepness and wetland inventories' GIS and satellite remote sensing have played an important role in collecting information, pinpointing sensitive and vulnerable forest, watershed and fragile marine ecosystems which are of critical relevance to the livelihoods of the most excluded sections of the population. They provide essential information on both the quantity and quality of forest land, wildlife and marine resources. GIS has also been instrumental in monitoring changes in forest land.

\section{Impact of ICT on Research and Extension}

The impact of ICT in agricultural research is quite significant. This is taking place through three means. The first one has to do with the changing nature of agricultural information systems, which is having a profound impact on how research results are communicated and disseminated. With the development of web-based information systems the possibility of accessing databases and information on-line has increased dramatically, with the concomitant problems that is generating from the point of view of the confidentiality of the information and of the economics of information management (economic value of information). The rapid expansion of web publishing is dramatically changing the way people access information, and is leading to the development of metadatabases. Based on virtual libraries that provide direct access to the publication, wherever it is located, as long as the publication is accessible through the web. Secondly, the very significant advances that are being made in software applications related to agricultural research techniques, coupled with advances in other areas of science, such as molecular biology, is accelerating the research process enormously and making it much more efficient. This is one of me areas hi which NARS can seriously fall behind, compared to lARCs, to ARIs and obviously to the private sector. Access to research software is one of the important dimensions through which die ICT technology gap can be avoided or reduced. But the most important impact on research is being generated by a third factor. The presence of new actors in agricultural research (such as the private sector. NGOs and universities), the changing composition of the scientific fields related to agricultural research (increasing importance of molecular biology and ICT as compared with agronomy and veterinary), the changing nature of networking, the possibility of working jointly with researchers in different institutional locations by interacting with them in real time, the possibility of developing virtual communities of scholars working on the same topic but dispersed in space, and the increasing importance of knowledge systems and learning systems that are based on interactive knowledge development processes, and thus on a different concept on how knowledge is generated and managed in this new environment, is leading to profound changes in the research world. The social organization of science is changing, given changes that are appearing in the organizational structure of research (how research is organized), as well as changes in the relationship between research, education and extension. The traditional linear relationship among these three functions is being replaced by dynamic interactive processes, based on knowledge systems that combine these three key functions in different and innovative ways.

\section{Rural and agricultural education}

Successful farming and agriculture require skill, and as local economies are forced to adapt to global exposure, rural education is increasingly important to keeping the rural poor both nourished and employed. At the same time, many rural schools operate tenuously, some relying on untrained or volunteer teachers necessarily disconnected from pedagogical training or dominance of the subject matter. ICTs are by no means a panacea for the general crisis in rural education, but they can offer help in some cases. ICT for agricultural education faces the same basic issues that characterize all ICT strategies - a need for connectivity, capacity building, and content development, supported by conducive governance. Simple repackaging of broadcast and other didactic content into new digital forms for rural people is one activity which can leverage the power of ICTs quickly, provided there solutions to access challenges, but the really new opportunities come from the interactive potentials of ICT systems, which can often compensate for gaps in a human instructor's specific subject matter dominance. With modern software and computing equipment, much educational content development for ICTs can be done inexpensively, but content is usually costly to do well. Nonetheless, low reproduction costs for digital materials means that the cost of good digital content development can be spread over a large number of beneficiaries. ICTs can benefit rural education in four important ways, each requiring progressively more support in infrastructure and human capacity building.

- ICTs providing teacher materials and curriculum support in agriculture

- ICTs as an additional skill or subject matter for students in the classroom.

- ICT as enrichment for existing courses, offering new pedagogical approaches

- ICT for rural distance education

Rural radio and interactive rural radio have played important roles in rural development, awareness building, and education. Community radio stations represent key intermediary organizations for whom Internet and other ICT accessibility (e.g., access to CD-ROM libraries of agricultural programming, linked to keyword searches) will allow radio stations to be more responsive to rural needs, provided that the social networks and incentives (e.g., 
linking to virtual communities in extension and agricultural research) are also in place .

\section{Developing business opportunities for farmers}

Agricultural development should focus on helping small farmers develop their operations as small businesses and take advantage of global trade opportunities by inserting themselves efficiently into the larger agribusiness sector. In this regard, creating mechanisms for small farmers to access, learn about, and contribute to the information networks that integrate global agribusiness is not only useful, but absolutely essential. Supporting ICT systems and training that link small producers to markets and provide technical support and guidance to enter higher value markets is one strategy. Access to ordinary and microcredit is increasingly seen as an essential strategy to promote business development in rural areas, including both farm credit and credit for off-farm activities. ICT systems, including computers, portable devices and "smart cards" are supplementing the information infrastructure that allows credit agencies to extend deeper into rural areas, produce credit risk/return profiles rapidly, and help both borrowers and creditors keep track of their repayment status and obligations (USAID, 2002). ICTs offer new income opportunities for rural families who have relatives in cities or abroad.

\section{Gender dimensions to rural agriculture}

The women in development community has been quick to recognize the value of ICT in meeting women's needs. It is also important to take the gender dimension of ICTs seriously from the earliest point possible, when gender norms about the new technology and its use are still forming. There is the Winrock's African Women's Leaders in Agriculture and the Environment program, funded by USAID, the Ford Foundation, and anonymous donors that build a cadre of women agriculturalists who could go on to influence policy and introduce gender perspectives into the male-dominated agricultural policy community. These women support each other by maintaining contact through email and informing each other of events through listservs to avoid isolation as a woman in a predominantly male environment. These women can also serve as electronic mentors to young girls who show promise in agriculture or policy circles. In societies that constrain male-female interaction and which also handicap women's educational opportunities, the effort to pass appropriate agricultural, health, or other information to women can be exceedingly indirect. ICTs may in many cases allow women to access information they require through a computer or cell phone, rather than have to interact directly with a man. ICT represents both a challenge and an opportunity for the empowerment of women. The increased prominence of ICT, in the absence of significant and sustained interventions to ensure equal opportunities for women in accessing new technologies, could serve to marginalize women further. However, ICT offers tremendous potential for the empowerment of women. ICT can help women overcome significant barriers that restrict their access to education, knowledge and information. Socio-cultural factors prevalent in many African countries place restrictions on the mobility of women. ICT can play an important role in eliminating the distance between women and information, and in overcoming cultural barriers to the acquisition of knowledge by women. ICT can be used by the disadvantaged women themselves or by organizations that specifically target these women ICT platforms allow information to be transferred across distance without face-to--face contact. As such it offers possibilities for women to engage in e-commerce, distance education, and e-government (Nnadi, et al, 2010).

\section{Improving rural governance}

Rural areas have traditionally been some of the most service-poor and neglected zones in rural governance and administration. ICTs can help reduce the effects of isolation and transport costs, and create mechanisms for greater accountability. Governance applications of ICT include:

- Training and support for local governments with new roles following decentralization

- E-Government assisted by or accessed by Internet or CD-ROM

- Access to government programs targeted at a specific region

- Local land titling registries

- Community resource management and monitoring

- Improved transparency

ICTs permit decentralized decision-making by allowing information to be shared inexpensively among dispersed decision makers. Local governments and community organizations not only gain access to development programs via ICTs but can also contribute input to program design. ICTs may help promote participatory mechanisms for citizens and transparent management of local resources by elected leaders by keeping track of public records available to all. It also can facilitate civic education campaigns and the implementation of national development projects. ICT is playing an important and vital role in agricultural production and marketing. ICT allows farmers to save time on order and delivery and getting feedback. In the existing competition, there is a need to rapidly attract new customers as well as retain existing customers. In order to take the real status of agricultural production and marketing, there is an urgent need to develop the following items:

1. Farmers' crop database must be managed. The database includes the kinds of crops, the size of cultivated area, time of harvest and yield. Farmers or the extension personnel transmit those data via the Internet to database server. Further, information provides the farmer with an important instrument for decision making and taking action.

2. Crops information service system should be created. This system analyzes the crop data to create some statistical tables. Farmers can access these statistical data by browsing the homepage and make their production plan. Changes within the structure of agriculture will probably have an impact on the 
selection and types of acquisition of software and other integrated systems made by the farmers.

3. Production techniques and information inquiry system should be created. This system integrates the production techniques and information, which are developed by experimental agricultural institutes and agricultural improvement stations. Farmers can find out relevant production information through this inquiry service system.

4. Production equipment's inquiry service system should be created. This system gathers information from the companies of seeds and crop production equipment to build the production equipment's inquiry service system. At the same time, allow relevant companies to access this system and enter their own data. Therefore, farmers can order the needed items through this system. Information is critical to the social and economic activities that comprise the development process. Development economy has witnessed four revolutions in agricultural (i.e. Green, white, yellow and blue revolution), bio-technological, industrial and information technology. Good communication system and information system reinforce commitments to sustainable productivity.

\section{ICT ROLE IN AGRICULTURE KNOWLEDGE MANAGEMENT}

Knowledge sharing, exchanging and dissemination are elements in a broader theme which is knowledge management. The central purpose of knowledge management is to transform our intellectual assets into enduring value (Metcalfe, 2005). The basic idea is to strengthen, improve and propel the organization by using the wealth of information and knowledge that the organization and its members collectively possess (Milton, 2003). It has been pointed out that a large part of knowledge is not explicit but tacit (Scheiber et al., 1999). This is true for knowledge in agriculture where a lot of good practices are transferred without being well documented in books, papers or extension documents. To manage the knowledge properly, ICT is needed. In effect, there are many information technologies that can be used for knowledge management. The following paragraphs describe these technologies and emphasize their roles in agriculture knowledge management. Content management system in its wider sense including data bases and multimedia, is the core technology of information and knowledge management. This technology can be used in different applications.

Building a national agriculture research information system (NARIS) needs to include research outcomes, projects, institutions and researchers in every country, and a regional research information system that works as a portal for all the NARIS. An example of NARIS has been developed at the Agriculture Research Center in Egypt (ARC, 2007).

$\rightarrow \quad$ Developing an information system of indigenous agricultural practices can enable researchers to examine this knowledge and decide on its usefulness for sustainable development. Such a system will also keep this knowledge for future generation before it disappear as a result of advanced technologies.

- Developing an information system recording matured technologies that on a trial basis have proven successful and success stories that have achieved economic growth will strengthen the interaction between inventors and innovators. This will lead to an innovation-driven economic growth paradigm

$\rightarrow \quad$ Storing and retrieving images, videotapes and audiotapes related to different agricultural activities.

Geographic Information System (GIS) are needed to store databases about natural resources with a graphical user interface that enables users to access these data easily using geographical maps. Decision support system techniques are needed in many applications:

$\rightarrow \quad$ Simulating and modeling methods can be used to build computer systems that can model and simulate the effect of different agricultural production policies on the economy and the environment to help top management make decisions.

- Using expert systems technology to improve crop management and track its effect on conserving natural resources is elaborated in Rafea (1999). This technology may also be appropriate for keeping indigenous knowledge (Rafea, 1995, 1998, 2000). Expediting the expert systems development by generating agriculture specific tools to overcome the well knowledge problem of knowledge acquisition is addressed in Abdul-Hadi et al., (2006). Enhancing the explanation capabilities of expert systems developed for agriculture was also investigated by Said et al., (2009). Modern ICTinternet and web technology is needed to make these systems available regionally and globally.

- Accessing the internet will bring a wealth of information to all agriculture stakeholders in rural and urban areas and will help in overcoming the digital divide. As most farmers in rural areas have no hands-on experience or access to digital networks, leaders of national agricultural research and extension system should be encouraged to consider the ICT option. Training farmers and extension workers, inducing women, in ICT will help them access a lot of useful information if each country tries to develop contents in the language people are using.

\section{THE SITUATION IN NIGERIA}

Right from the inception of the ADP strategy, starting with the pilot/enclave ADPs and using the $\mathrm{T}$ and $\mathrm{V}$ extension delivery, the development support communication component of the strategy has made every significant contribution to the country's agricultural development. It started with the mobile cinema vans going from village to village and supported with minimum extension publications in local languages. Then radio and mobile video vans and television was added with the world bank assistance. The radio and the TV programs grew with the growth of the 
ADPs, and the creation of states in the country, from the original 3 regions to now, 36 states and the Federal Capital Territory (FCT). By the commencement of the National Agricultural Technology Support Project (NATSP) which was the second development phase (1991-1996) of the World Bank loan facility support for the ADPs, virtually all the projects had well developed and equipped Development Support Communication (DSC) units, with video, radio and television production and viewing facilities. All the ADP radio and TV programs were initially aired free on the states' and some of the National Broadcasting Networks. With the commercialization of the both the states and National Networks, the frequency of both ADP radio and TV Programs, dropped appreciably due to financial constraints. To date, it is the radio and TV and that have been the major ICTs used in agricultural extension delivery in Nigeria.

Despite the importance of these channels, it must be stated that the channels are still principally owned and controlled by either the state or federal government. Unlike the case in several francophone West African countries, rural and/or community-based radio is virtually unknown in Nigeria. Also, the information content of these channels is more provider-driven than user-driven and this has serious implications for extension delivery. Telephone use in extension delivery, even, with the launch and explosion of the global system of mobile communication (GSM) as a dividend of democracy in Nigeria is very limited as most ADPs even at the headquarters do not have functional lines. The serious limitations of access to reliable telephone lines makes even ordinary intra-and inter-organizational networking for information exchange a harrowing and frustrating experience (Arokoyo, 2005).

Although most of the organizations in the national agricultural research and extension system (NARSS) now have compute for information and data managements, most of the computers have neither telephone nor internet access. Consequently, a substantial number of research institutes and extension organizations have no E-mail contacts. In conclusion, even though ICTs use for extension delivery in Nigeria is relatively limited, particularly as it affects the information technology users i.e. the farmers, use of radio and TV has made significant development in Nigeria.

Currently in Nigeria, agricultural information comes mainly from research institutions, which generates new technologies to farmers. It thus follows that the agricultural research information service center is the custodian of several information resources including CD-Rom databases (which could be bibliographic, research, factual), multimedia knowledge bases, in house publication. Other sources may include agricultural information providers such international organizations and local non-governmental organizations and local non-governmental organization and community based organization. The main modes of delivery are farmers' magazines, newspaper, posters, leadflats, handbooks, radio, television, films and videos. However, there are ample rooms for testing other forms of information dissemination, such as the mobile telecommunication system (Omotayo, 2005).

Whereas access to ICT is largely available in cities, opportunities for including the rural communities now do exist, particularly with the development of technologies like the small low earth orbit satellites like the Nigerian sat 1 and 2 .

\section{Challenges of Ict Use in Agricultural Extension In Nigeria}

There are still very serious limitations for ICT use; particularly in the rural areas despite the world-wide ICT revolution. Principal one among these are:

$\rightarrow \quad$ The low-level ICT readiness of' not only the Research and Extension organizations but indeed of the developing countries themselves. Most developing countries have very poorly developed ICT infrastructural facilities including poor and limited number of telephone lines, most of which are still in the analogue mode.

$\rightarrow \quad$ Very low level capacities of gateways and portals to international networks/satellite systems.

$\rightarrow \quad$ Erratic and unstable power supply and high cost of alternative power through standby generators.

$\rightarrow \quad$ Limited and very high cost of telephone services either by land lines or GSM. It has been estimated that Nigeria has the highest GSM call rates in all developing countries that have the facility. Whereas the telephone is part of everyday normal life in developed countries and ordinarily taken for granted, it is a different matter in developing countries where it is either non-existent, terribly limited, services very abysmal and cost astronomical. The teledensity for Nigeria is about 1 for 400 - 500, not comparable to South Africa. Despite the phenomenal rise in the availability and access to phone lines, the extension service has NOT taken commensurate advantage to exploit the opportunity.

- Limited access to computers and even worse access to the internet, making even basic inter and intra organizational networking for information exchange almost impossible. Lack of a communications policy by governments of most developing countries or policy inconsistencies in the sector that discourage private sector investment.

$\rightarrow \quad$ High level rural poverty;

$\rightarrow \quad$ High level illiteracy of farmers and computer illiteracy among researchers, and extension Limited access to world-wide databases on CD- ROMs or DVDs due to foreign exchange constraints.

With respect to the Internet, major problems to contend with include; content. The vast majority of sites are not relevant to rural people and it is quite a problem finding the few sites that have the technical information on agriculture market information and useful contacts that are relevant to their needs.

\section{Lessons for Nigeria}

In order to catch on the potential benefits of ICT, there coherence among ICT related activities and initiatives. In order to catch on the potential benefits of ICT, there is a need for promotion of basic education and ICT knowledge 
among the rural dwellers. In this regard, emphasis should be laid on raising the rural dwellers' awareness of the emerging ICT opportunities and training them on effective use of the ICT devices for specific purpose. It is suggested that the ICT training programme should focus on different groups of people, such as development workers, rural youths, women and farmers groups, with a view to making ICT usage cut across all the social and economic strata in the rural areas. In order to avoid wastage of economic resources and ineffective ICT diffusion, ICT infrastructural development should be made relevant to the needs of users. It should be compatible with the situation of the rural people. This calls for a participatory needs assessment of the rural areas in order to be able to establish the right kind of ICT required by the people and what the information content should be. Appropriate use of ICT in this regard would bring about efficient and sustainable usage of the ICT among rural people. For a proper ICT development in Nigeria, there is need to put in place a legal, institutional and regulatory framework that would ensure a pro-people ICT policy in which attention would be given to areas where people in general could derive the most benefit from ICT usage or where it could have the greatest positive impact on overall national development. In order to achieve this, Awe (2007) stresses the importance of a multi-stakeholder approach in which public institutions, private sector, civil society, academic, ICT industry, consumers, small and medium scale enterprises and the public would be involved in the development of ICT policies and implementation strategies. This step is essential to ensuring that such strategies are well grounded in reality. In addition, a holistic approach that recognizes and resolves conflicts, overlaps and gaps is equally essential as this would help meet ICT users' need for close coordination and coherence among ICT related activities and initiatives.

\section{Strategies for Improvement}

The following measures could be taken to address the ICT problem in Nigeria:

\section{Develop State-of-the Art ICT Infrastructure to Connect key Stakeholders by}

A) Providing Telephone, ICT (Internet) and SATCOM satellite communication linkage), video conferencing connectivity to all states, the ADPs and research institutes: Providing required hardware and software to all the above institutions. Creating ICT Training and Consultancy Infrastructure at National, State and Local Government areas;

B.) Creating ICT awareness among all stakeholders nationally: Capacity building of all the extension functionaries and scientist at research institutes, the ADPS and REFILS coordinating centres; creating ICT training material at national and state level training institutions.

C.) Create information packaging mechanisms at key participating agencies: Capacity building of all the extension scientists at ADPs and national research centres in information packaging; Integration of Agricultural marketing Data (including market prices, marketing intelligence and state/specific forecasts) with extension information delivery' Integration of information on allied subjects like animal Husbandry/Horticulture/sericulture, agroforestry; healthy etc. with the extension information (making it holistic for the farmer.

D.) Create a Nodal cell in each state to monitor the progress of cyber extension on regular basis: A Nodal cell with full connectivity with all National Agencies to ensure appropriate policy input at state level providing technology ICT support to all these agencies.

E.) Identify a National Co-ordinating Agency for "Cyber Extension" in Nigeria. If the idea of cyber extension is adopted in Nigeria, the process has to be complemented by expensive on-line networking of farmer service providing agencies" from the national agencies up to state ADPs nationwide and where possible the zonal and block-levels in each state.

\section{Using Web-Based Portal To Optimize The Linkage System}

In order to optimize the research-extension farmer-input linkage system we proposed a research portal to be called web-based online extension system as a bridge between research stations, extensionists and end-users of agrotechnologies. The portal will have a front-end comprising all the consumers of research results, while the Based-End comprised a database of researches from the research stations, to be centrally hosted by Agricultural Extension Department/Unit of each faculty of Agriculture/Research Institute. The agricultural extension units of research institutes would serve as a pivot of research information. The results would be posted to the extension web site. Farmers, extension agents and agro-industrialists would view the net at any local resource centre. The job of the conventional extension agent would be to concentrate on tasks and services where human interaction is essential in helping farmers, individually and in knowledge in farm activities. Extension workers will engage farmers (especially illiterate farmers) in the search and packaging of information on demand and interpreting research results. Apart from posting research results to the farmers, the portal has a portfolio that would enable the consumers of research results post their contemporary problems to the research stations through the central database of the web.

\section{Conclusion}

Information and communication technology for development is a phenomenon as well as a medium that' has radically improved interaction throughout the world. Thus, there is the need to develop a strong linkage complimented by flawless information flow enhanced through the effective use of information and communication technologies by the extension service to significantly boost agricultural production and improve rural livelihoods in Nigeria. This will enhance the quality of interaction between extension agents and their clientele instead of moving "messages" through a long chain of hierarchical system. The web-based system would not only strive to generate high-yielding agricultural technologies that are sufficiently adapted and relevant to specific local environments, but also provide useful services needed to raise the quality of life by accelerating the diffusion and mass adoption of new 
technologies on Nigerian farms. An effective information technology does not only create demand for but also supply information package that are desired to undertake necessary modifications of given technologies or help to plan new agricultural research agenda.

\section{References}

1. Abdul-Hadi, Z. (2006). Rapid Generation of Plant P r o t e c t i o $n$ Expert Systems Computers in Agriculture and Natural Resources. Proceedings of the 4th World Congress Conference Orlando, Florida, USA. 24th- 26th July.

2. ADB (2003). A Strategic Approach to Information and Communities Technology Toward E-Development in Asia and $\mathrm{t} h \mathrm{e}$ Pacific. Asian Development Bank.

3. Arokoyo ., T. (2005). ICTs Application in Agricultural Extension Service Delivery. In Adedoyin, S.F. (ed) Agricultural Extension in Nigeria, Agricultural and Rural Management Training institute, ILorin.

4. ARC (2007). National Agriculture Research Information Management System (NARIMS). Agriculture Research C e n tr e, Egypt.

5. Awe, J. (2007). ICT policy for Development. Available at www.jidaw.com/digitalnigeria,html.

6. Bheenick, K.J. and Brizmohun, R. (1999). The Scope of Information Technology Applications in Agricultural Extension in Mauritius, University of Mauritius Special Paper.

7. Eastman, J.R., Anyamba. A. and Ram Chandra .M. (1996). The Spatial Manifestations of ENSO Warm Phase Events in Southern Africa. The Clark Labs for Cenotaphic Technology And Geographic Analysis. Clark University, Worcester, U.S.A.

8. Metcalfe, A.S. (2005). Knowledge Management and Higher Education: A critical Analysis. Available online at http//site.ebrary.com/tub/aucairo/Doc?id=.

9. Milton, N. (2003). Knowledge management. Available at www.epistemics.co.uk/Notes/40-0-0htm.

10. Mundy, P. and Sultan, A. (1999). Information Revolutions: How Information and Communication Management is Changing the Lives of Rural people. Technical Centre for Agriculture and rural Co-operation, Wagenigen, The Netherlands.

11. Munya, H. (2000). Application of Information and Communication Technologies in the Agricultural Sector in Africa. A Gender Perspectives. In Rathogeber, E. and Adera, E.O.

(Eds) Gender and Information Revolution in Africa. ADRC/ECA.

12. Nnadi, F.N., Chikaire, J., Ejiogu-Okereke, N. and Nwakwasi, R. N . (2010) Information and Communication Technology ( ICT) For Food Production and Distribution. Proceedings of the 44th Annual Conferences of Agriculture Society of Nigeria Held at Ladoke Akinkal University of Technology, Oyo State. 18th-22nd October.

13. Omotayo, A.M. (2005). Information Communication Te c h n o l og y and Agricultural Extension: Emergency Issues in $\mathrm{T} \mathrm{r}$ a $\mathrm{n} \mathrm{s}$ f e $\mathrm{r} \mathrm{r}$ i $\mathrm{n} \mathrm{g}$ Agricultural Technology in Developing Countries. In Adedoyin, S.F. (ed) Agricultural Extension in Nigeria, ARTMI. ILorin.

14. Rafea, A. (1995). Expert Systems as a tool for Information Technology in Agriculture. International Informatics, Singapore.

15. Rafea, A. (1998). Agriculture. In Liebwitz, J. (ed) Handbook Applied Expert Systems. CRC Press, Boca Raton.

16. Rafea, A. (1999). Natural Resources Conservation and Crop Management Expert Systems. In Kersten, G. (ed) Decision Sup p ort
Systems for Sustainable Development. IDRC and Kluwer Academic Publis

17. Rafea, A. (2009). Managing Agriculture Knowledge: Role of Information and Communication technology. Thinkpiece for CGIAR Science Forum Workshop on ICTs Transforming Agricultural Science, Research and Technology Generation. Wageningen, Netherlands 16-17 June.

18. Richardson, D. (2003). Agricultural Extension Transforming ICTS? Championing Universal Access. Background paper for CTAs ICT Observatory.

19. Said, A., Rafea, A. El Baltagy, S. and Hassan, H. (2009) Automatic Generation of Explanation for Expert Systems Implemented with Different Knowledge Representations. WSEAS. TRANSACTIONS ON SYSTEMS issues 1 volume 8

20. Schreiber, G., Akkermans, H., Anjewiderden, A., De Hoog, R., Shadbolt, N., and Van de Velde, W. (1999). Knowledge Engineering and Management. The Common KADs Methodology. MIT Press, Cambridge.

21. Sharma, V.P., (2003). Improving Access Information Management Geographic Information Systems (GIS) Development Proceedings India.

22. Spore (2004). Information and Communication Technology: Poor But Plugged. Information for Agricultural Development in ACP Countries. Spore Magazine No 110, Leusden, CTA.

23. USAID (2002) ICT for Development Strategic Plan. United S t a t e s Agency for Information Development, Washington D.C. 